\title{
Integrating Ethnicity and Migration As Determinants of Canadian Women's Health
}

\author{
Bilkis Vissandjee*1, Marie Desmeules², Zheynuan $\mathrm{Cao}^{3}$, Shelly Abdool ${ }^{4}$ and \\ Arminée Kazanjian 5
}

\author{
Address: ${ }^{1}$ School of Nursing Sciences, University of Montreal, Montreal, Canada, ${ }^{2}$ Centre for Chronic Disease Prevention and Control, Health \\ Canada, 120 Colonnade Rd, Ottawa, Canada, ${ }^{3}$ Centre for Chronic Disease Prevention and Control, Health Canada, 120 Colonnade Rd, Ottawa, \\ Canada, ${ }^{4}$ School of Nursing Sciences, University of Montreal, Montreal, Canada and ${ }^{5}$ Faculty of Medicine, The University of British Columbia, \\ 5804 Fairview Ave, Vancouver, Canada \\ Email: Bilkis Vissandjee* - bilkis.vissandjee@umontreal.ca; Marie Desmeules - Marie_desmeules@hc-sc.gc.ca; \\ Zheynuan Cao - Zhenyuan_cao@hc-sc.gc.ca; Shelly Abdool - shelly.n.abdool@umontreal.ca; Arminée Kazanjian - a.kazanjian@ubc.ca \\ * Corresponding author
}

from Women's Health Surveillance Report

A Multidimensional Look at the Health of Canadian Women.

Published: 25 August 2004

BMC Women's Health2004, 4(Suppl I):S32 doi:I0.I I86/I472-6874-4-SI-S32

This article is available from: http://www.biomedcentral.com/I472-6874/4/SI/S32

\begin{abstract}
Health Issue: This chapter investigates (I) the association between ethnicity and migration, as measured by length of residence in Canada, and two specific self-reported outcomes: (a) selfperceived health and (b) self-reports of chronic conditions; and (2) the extent to which these selected determinants provide an adequate portrait of the differential outcomes on Canadian women's self-perceived health and self-reports of chronic conditions. The 2000 Canadian Community Health Survey was used to assess these associations while controlling for selected determinants such as age, sex, family structure, highest level of education attained and household income.
\end{abstract}

Key Findings: - Recent immigrant women ( 2 years or less in Canada) are more likely to report poor health than Canadian-born women ( $O R=0.48 \mathrm{Cl}$ : 0.30-0.77). Immigrant women who have been in Canada 10 years and over are more likely to report poor health than Canadian-born women $(\mathrm{OR}=1.3 \mathrm{I} \mathrm{Cl}$ : I.18-1.45).

- Although immigrant women are less likely to report chronic conditions than Canadian-born women, this health advantage decreased over time in Canada (OR from 0.35 to 0.87 for $0-2$ years to 10 years and above compared with Canadian born women).

Data Gaps and Recommendations: - Migration experience needs to be conceptualized according to the results of past studies and included as a social determinant of health above and beyond ethnicity and culture. It is expected that the upcoming longitudinal survey of immigrants will help enhance surveillance capacity in this area.

- Variables need to be constructed to allow women and men to best identify themselves appropriately according to ethnic identity and number of years in the host country; some of the proposed categories used as a cultural group may simply refer to skin colour without capturing associated elements of culture, ethnicity and life experiences. 


\section{Background}

Given the increasing diversity of Canadian society, ethnicity and migration experiences are both important issues to consider when examining the social determinants of women's health. [1-7] Immigrants represent a large and increasing segment of the Canadian population. In 2001, over 5 million Canadians (about $18 \%$ of the population) were born outside of the country, and each year approximately 250,000 new immigrants are received. Immigrant women, women refugees and women of diverse ethnic backgrounds form an increasingly large percentage of the Canadian "mosaic": up to 38\% of Canadian women are neither French nor British in origin. [8,9] The body of research on the relation between ethnic background and health suggests that immigrant subgroups may be vulnerable in terms of health status, health service use and determinants of health. [7-16] As well, it has been shown that various mechanisms affect the relation between ethnicity, migration and health.[10,11,13]

Health status research suggests that recent (less than 2 years of residence in the host country) immigrants (particularly from non-European countries) are, upon their arrival, healthy overall, with notable exceptions for some health conditions, such as certain infectious diseases. [1016] However, after 10 years of residence in Canada, the prevalence of a number of chronic conditions and longterm disability approaches the levels found in the Canadian-born population.[12,13] Explanations for this "healthy migrant effect" among recent immigrants may include selection bias and healthy behaviours, such as low rates of tobacco use, as well as spurious research findings due to methodological limitations. $[1,2,14,15]$ However, comprehensive information that includes sex and gender differences in how migrants and ethnic groups experience health is still lacking. More specifically, a number of studies have shown that it is timely to assess the health of women and men with respect to ethnicity and migration experiences, in order to contribute to the understanding of the complexity attached to these concepts.[10,13-15]

Just as gender has been discussed in the various sections of this Report as an essential social determinant of health, diversity is as essential. Indeed, Health Canada, along with the Canadian Centres of Excellence on Migration and the Centres of Excellence for Women's Health Program, strongly recommend a diversity analysis as a complement to the now widely accepted gender-based analysis. [15-17] Incorporating diversity based on ethnicity and migration into health analyses requires accounting for the subtleties of distinction between women and men.[15-19,23]. Diversity results in differential life experiences and opportunities among the heterogeneous group of Canadian women and men. Studies have shown that determinants such as skin colour, immigration and refugee status, coun- try of origin, age at migration and experience with discrimination shape each person's unique identity and, in turn, will affect his or her health and well-being. [22-27] Evidence suggests that migration experiences - above and beyond ethnicity - are as strongly correlated with migrant health as are limited education and lack of access to material resources. While a number of studies have explored ethnicity and health, Cooper and Nazroo indicate that ethnicity has been a neglected dimension in comparative studies of gender and health.[28,29] Similarly, Kinnon, on the basis of her review of the literature, stated that migration experiences have not been systematically investigated in terms of their association with health along with gender and ethnicity.[15,16]

\section{Immigrants to Canada}

In Canada, immigrants are usually "classified" according to four major classes: independent immigrants (including nominated relatives), business class immigrants, family class immigrants (who are sponsored by either independent immigrants or family members who are already residing in Canada) and refugees (who are further subdivided into two classes).[30] China, India, Pakistan, the Philippines and the Republic of Korea were represented among the top 10 source countries for migration to Canada in 2001. The top three regions of origin were Asia and the Pacific (53\%), Africa and the Middle East (19\%), and Europe and the United Kingdom (17\%). In 2001, 61\% of immigrants fell into the independent class category, $27 \%$ into the family class category, $11 \%$ into the refugee category and $1 \%$ into a category labelled "other". The leading four source countries for refugees in 2001 were Afghanistan, Sri-Lanka, Pakistan and Yugoslavia.[9,31,32]

The Immigration Act establishes a multi-tiered system of rights and privileges among immigrants based on a points system to determine eligibility. Points need to be earned in nine categories, such as education, language and occupation. Usually, when a two-parent family applies for landed immigrant status, only one member in the family is granted the independent status. In most cases, it is the husband who is so designated, because he is perceived to be the head of the household; the wife is categorized as a family class immigrant along with the children. This classification ignores the fact that the wife may have comparable education and work experience to her husband, and may have made an essential contribution to the family income before immigration.[28,33-36]

Migration experiences and their effects on health have received attention very recently.[10,15,29,37] Migrating represents a significant transition in the move from the homeland to a new home, and brings with it many material and psychosocial losses.[22,23,37] This transition can produce profound shifts in people's lives, involving short- 
to long-term implications for health and well-being. [3840] Immigrant women may experience increased vulnerability related to settlement, isolation and attainment of the basic needs of the family with limited knowledge of resources in the host country. Such vulnerability potentially exposes them to differing structural, interpersonal, cultural and economic threats to their health and wellbeing.

Migratory experiences are arbitrarily conceived in three parts: pre-migratory includes those experiences that take place from the moment a decision is taken to emigrate (regardless of who in the family unit makes this decision); settlement experiences refer to those events after arrival in the host country and up to 5 years after migration; and the post-migratory experience refers to years 6 to 10 after migration. Each phase represents different processes of progressive integration and thus should be considered as having differential effects on health.

The label "immigrant woman" does not simply refer to a legal status but encompasses a set of complex realities and experiences. Midiema et al.[41] argue that "immigrant woman" combines technical, legal and social criteria. It is of importance to note that the term "immigrant" often refers to a person who has either acquired permanent resident status in Canada with the rights of Canadian citizens or has actually become a Canadian citizen. On the other hand, when viewed as a social construct, the term "immigrant woman" usually refers to women of colour, women who do not speak English (or French) very well or without an accent other than British or American (or French), and women who occupy lower positions in the occupational hierarchy.[22,23,40]

\section{The Concept of Ethnicity}

There has been much debate surrounding the use of concepts such as "ethnicity", "race" and belongingness to a specific group. Ethnic groups do not refer to homogeneous populations; they include broad categories usually based on age at migration, length of residence, source country/ethnicity, knowledge of host country languages, health status and health behaviour.[10,17,28,36-38] These categories are a useful start in acknowledging diversity among groups of people. Yet these terms also have certain limitations by way of capturing the interaction between biology and the socio-environmental circumstances that are known to contribute to differential experiences in health. [22-24] As Davey Smith rightly points out, recognition of the need to analyze ethnicity and socio-economic position as separate variables in health studies raises a number of issues, including the importance of assessing whether conventional measures of health status and of socio-economic position are sensitive enough for different ethnic groups.[10] Yet another issue is that categories of "race" have often led to the undercounting of those who self-identify outside of the prescribed racial groups (e.g. White, Black, Asian).[39,40] These issues lead to the recognition that different ethnic/ racial groups do experience discrimination based on sex and ethnic background. Discrimination can vary in form, depending on how it is expressed, by whom and against whom, and it can occur in all aspects of life. In turn, it affects perceptions of health and health behaviour.[17,22,24,28,35,38-45]

Health is known to be influenced by socio-economic position, and it has also been argued that the socio-cultural context, which includes cultural and migratory experiences, of women and men shapes exposure to healthdamaging agents as well as determining individual resources to promote health $[17,28,42,46]$ (see also the chapter on Social Context in this Report). Aside from discrimination, as mentioned above, the literature attests to the importance of cultural variations and migration experience in perceptions of health and what makes one ill or healthy.[17,21,47-53] A number of studies also show that the process of acculturation or progressive integration produces changes in health.[7,54-56] To investigate these changes in health and disease patterns during migration, research has traditionally relied on methods using at least two groups: those born in the host country (a category within which first, second and third generation could be assessed) and those born outside. The number of years spent in a specific country in lieu of assessing acculturation or progressive integration has recently been used to explain determinants/variables of health and well-being of women and men migrating to Canada. Research suggests that different dimensions of the progressive integration process may be associated with different types of outcomes.[17,48,54] However, few studies have investigated health status or chronic conditions as perceived by a diversity of populations and according to the number of years since arrival in a host country.[13,28,29,55-58]

In order to increase our understanding of the social determinants of health in ethnic groups undergoing migration experiences, this chapter seeks to investigate the differential association between self-assessed ethnic affiliation and length of residence in Canada since migration, while controlling for selected socio-economic determinants of health such as age, smoking status and two specific outcomes among Canadian women and men, namely (a) self-perceived health and (b) self-reported chronic conditions.

\section{Methods \\ Data Sources and Measures}

Cross-sectional data from the Canadian Community Health Survey (CCHS) - Cycle 1.1 (2000) were analyzed 
Proportion of self-reports of chronic conditions among women who report lower / higher income by length of residence Source: CCHS, 2000

Lower income women

Reporting chronic conditions

length of residence in Canada : 0-2 years43,68 length of residence in Canada : 3-9 years45,65 length of residence in Canada : 10+ years75,15 Canadian born women 76,25

Higher income women

Reporting chronic conditions

length of residence in Canada : 0-2 years 44,58 length of residence in Canada : 3-9 years 49,06 length of residence in Canada : 10+ years71,70 Canadian born women 69,97

\section{Figure 4}

and reported chronic conditions was similar to that of Canadian-born individuals, at $72 \%$ and $70 \%$ respectively.

The results of the logistic regression multivariate analyses are presented as odds ratios (OR) and their 95\% CIs (Figures 5 and 6). Logistic regression analyses are useful for describing the simultaneous relationship of a group of continuous and/or categorical independent variables and a dichotomous outcome variable, namely self-perceived health and reports of chronic conditions $[57,59,61,64,66]$. The relative odds express the amount of increase in the outcome that would be produced by one unit increase in the independent variable. In order to avoid obscuring gender and ethnic differences, as can occur when combining both sexes in multivariate models or age-adjusted health outcomes, the models in these analyses were set up separately for women and men. $[2,6,7,15,16,27,28]$ Since a large number of variables were controlled for simultaneously (age and socio-economic position, including employment status, marital status, educational attainment, income adequacy, dwelling security and food insecurity $[17,35,38,42,43,46,57,60])$, it was deemed important to assess the stability of the model in order to rule out biased results due to multicollinearity. Model fit statistics showed that the models are significant. Pearson correlations were also performed. Coefficients demonstrated weak to moderate associations between each two given variables, indicating a fairly stable multivariate model.
Analyses show that immigrant women who have been in Canada for less than 2 years are less likely to report poor health than Canadian-born women $(\mathrm{OR}=0.48, \mathrm{CI}$ : 0.30, $0.77)$.

As discussed earlier as well as by a number of authors, $[10,12-16,21,28,29,37,38,48,51,57-60]$ this "healthy immigrant effect" disappears over time. Women who have migrated to and resided in Canada for at least 10 years and over are more likely to report poor health than Canadian-born women $(\mathrm{OR}=1.31$, CI: 1.18,1.45). Among men, the protective effect of length of residence wears out from between 2 and 9 years of residence, but no significant differences are shown after 10 years and over of residence in Canada between the long-term migrant men and Canadian-born men.

With respect to the association of ethnic affiliation and self-perceived health, controlling for confounders, women who indicated that they were of South Asian origin were more likely than Canadian women to report poor health $(\mathrm{OR}=1.42, \mathrm{CI}: 1.06,1.91)$. Among men, those who identified themselves as Black were less likely than their Canadian counterparts to report poor health, whereas the opposite was observed for men of Western European origin (OR $=1.16, \mathrm{CI}: 1.03,1.31)$.

Controlling for confounders as indicated above, clearer patterns by length of residence in Canada were observed for both women and men when self-reported chronic conditions were considered as an outcome variable. Women and men were both less likely than Canadian-born individuals to report chronic conditions. However, as the years of residence in Canada increase, the protective effect becomes progressively less for both groups. This gradient shows a gradual loss over time of the health advantage that migrant women (for 0-2 years of residence, OR = $0.35, \mathrm{CI}: 0.27,0.46$ and for $10+$ years of residence, $\mathrm{OR}=$ $0.87, \mathrm{CI}: 0.79,0.95$ ) and men (for $0-2$ years of residence, $\mathrm{OR}=0.42, \mathrm{CI}: 0.33,0.55$ and for $10+$ years of residence, $\mathrm{OR}=0.82, \mathrm{CI}: 0.75,0.90)$ are known to enjoy upon arrival in the host country.

With respect to the association between ethnic affiliation and self-report of chronic conditions, controlling for confounders, women who indicated that they were of South Asian (OR $=0.60, \mathrm{CI}: 0.48,0.75)$ as well as of Chinese (OR $=0.64$, CI: $0.53,0.77$ ) origin were less likely than Canadian women to report chronic conditions. On the other hand, women self-assessing themselves as Western European were more likely to report chronic conditions $(\mathrm{OR}=$ 1.14, CI: 1.05,1.24). Interestingly, a similar pattern between the same ethnic affiliation groups and Canadian men was observed. 


\section{Figure5. Adjusted ${ }^{*}$ oddsratios of self-reports of poorhealth by lengthof residenceandethnicaffiliation}

\begin{tabular}{|c|c|c|c|c|c|}
\hline \multirow{2}{*}{\multicolumn{2}{|c|}{ Selected determinants }} & \multicolumn{4}{|c|}{ Odds ratios $95 \%$ Confidence interval } \\
\hline & & Men & Women & Men & Women \\
\hline \multirow{4}{*}{$\begin{array}{l}\text { Length of } \\
\text { residence in } \\
\text { Canada since } \\
\text { migration }\end{array}$} & Canadian born $\bullet$ & - & - & - & - \\
\hline & $0-2$ years & $0.55 *$ & $0.48 *$ & $0.31,0.99$ & $0.30,0.77$ \\
\hline & $3-9$ years & $0.63 *$ & 0.96 & $0.44,0.88$ & $0.74,1.26$ \\
\hline & 10 years + & 1.10 & $1.31 *$ & $0.98,1.24$ & $1.18,1.45$ \\
\hline \multirow{5}{*}{$\begin{array}{l}\text { Ethnic } \\
\text { affiliation }\end{array}$} & Canadian• & - & - & - & - \\
\hline & Chinese & 1.14 & 1.01 & $0.82,1.60$ & $0.75,1.36$ \\
\hline & South Asian & 1.03 & $1.42 *$ & $0.70,1.51$ & $1.06,1.91$ \\
\hline & Black & $0.40 *$ & 1.27 & $0.19,0.85$ & $0.78,2.06$ \\
\hline & Western European & $1.16^{*}$ & 1.02 & $1.03,1.31$ & $0.91,1.13$ \\
\hline
\end{tabular}

¥ determinants adjusted for are as follows: age, marital status, educational attainment, income adequacy, dwelling security, food insecurity and employment status;

-Reference group

*Significance level $p<0.05$

Source: CCHS 2000

Figure 5

\section{Discussion}

One limitation of our analysis is that the use of cross-sectional data makes it difficult to disentangle the direction of causality and thus limits the ability to exclude the potential for reverse causation.[8,10-13] Nonetheless, controlling for determinants such as age and socio-economic position, complex variables such as ethnic affiliation and/or country of origin remain associated with selfreported measures of health known to be rather subjective and culturally bound measures of health. $[13,17,28,29,42,43,61]$ Women who had been in Canada for at least 10 years and over were significantly more likely to report poor health than recent immigrant women; for men, being in Canada at least 10 years and over did not make a significant difference. This attests to the differential needs and patterns of reporting unmet needs of care between women and men who experience migration.
These results are convergent with the study by Dunn and Dyck[13] of the social determinants of health in Canada's immigrant population using the NPHS (1994-1995). They found some consistent pattern for length of residence in Canada and reports of chronic conditions by women and men. Their data also showed that as length of residence increased, women and men were more likely than the Canadian-born population to report poor health status. They explain these findings by the fact that age is certainly associated with reports of poorer health status among the migrant population, as is the case with older Canadians in general.

With respect to self-reports of chronic conditions, women who had experienced migration were less likely to report chronic conditions than Canadian-born women, and the gradient among women according to their years of residence in Canada was steeper than for men. Furthermore, 


\section{Figure6. Adjusted ${ }^{*}$ oddsratios of self-reports of chronicconditions by lengthof residenceandethnicaffiliation}

\begin{tabular}{|c|c|c|c|c|c|}
\hline \multirow{2}{*}{\multicolumn{2}{|c|}{ Selected determinants }} & \multicolumn{4}{|c|}{ Odds ratios $95 \%$ Confidence interval } \\
\hline & & Men & Women & Men & Women \\
\hline \multirow{4}{*}{$\begin{array}{l}\text { Length of } \\
\text { residence in } \\
\text { Canada since } \\
\text { migration }\end{array}$} & Canadian born• & - & - & - & - \\
\hline & $0-2$ years & $0.42 *$ & $0.35 *$ & $0.33,0.55$ & $0.27,0.46$ \\
\hline & $3-9$ years & $0.47 *$ & $0.41 *$ & $0.38,0.57$ & $0.35,0.48$ \\
\hline & 10 years + & $0.82 *$ & $0.87 *$ & $0.75,0.90$ & $0.79,0.95$ \\
\hline \multirow{5}{*}{$\begin{array}{l}\text { Ethnic } \\
\text { affiliation }\end{array}$} & Canadian• & - & - & - & - \\
\hline & Chinese & $0.74 *$ & $0.64 *$ & $0.59,0.92$ & $0.53,0.77$ \\
\hline & South Asian & $0.64 *$ & $0.60 *$ & $0.52,0.80$ & $0.48,0.75$ \\
\hline & Black & 0.66 & 1.00 & $0.44,1.00$ & $0.72,1.40$ \\
\hline & Western European & $1.19 *$ & $1.14 *$ & $1.10,1.28$ & $1.05,1.24$ \\
\hline
\end{tabular}

¥ determinants adjusted for are as follows: age, marital status, educational attainment, income adequacy, dwelling security, food insecurity and employment status;

-Reference group

*Significance level $p<0.05$

Source: CCHS 2000

Figure 6

women and men identifying themselves as having Western European origin were more likely to report chronic conditions. Similar results were obtained by Dunn and Dyck using the NPHS.[13] Our descriptive data showed that those who identified themselves as having Western European origin were older and more established immigrants, and this may partly explain the likelihood of reports of chronic conditions among women and men who migrated to Canada a long time ago.

These trends in research results raise the possibility that socio-economic inequalities cannot fully explain ethnic inequalities in health. $[51,54]$ This very measure is culturally bound. As Nazroo points out,[51] "It is important to recognize that the process of standardization for socioeconomic position when making comparisons across groups, particularly ethnic groups, may not be so straightforward." In cross-cultural research, the heterogeneity of women and men who constitute the population experi- encing migration needs to be accounted for, not only with respect to their country of birth, but also the country of origin, the migratory trajectory and the actual experiences of migration as they relate to health.

Variables such as migration, as measured here by length of residence in Canada, as well as self-reports of ethnic affiliation are indeed complex variables; they need to be examined in conjunction with variables such as age at migration, conditions of migration and socio-economic conditions across the life course. $[22,25,27]$ The progressive integration process also needs to be examined with a more systematic gender perspective. Language spoken inside and outside the home, values and religious observances may be associated with different aspects of the progressive integration process; the latter may occur differentially between women and men. Indeed, the relation between taking on host country culture and relinquishing the culture of origin is not reciprocal, as a strict 
assimilation model would imply; therefore, acculturation is not a linear process, simultaneously invoking health risk and protective environment.[14,17,61-67] Furthermore, it has also been shown that ethnic differences in self-reported health cannot be assumed to be a consequence of cultural differences between immigrant groups.[22-24,28,38,54,61]

Examining migration as a determinant of health requires more research and debate on the methods of measuring ethnicity and migration variables that would better account for gender and diversity in the experiences of migration as time of residence in a host country increases. Some have argued that it is time to abandon the assessment of race/ethnicity in public health research.[68] Others, including a number of authors in this Report, insist that collecting gender, ethnicity and migration data along with other social determinants of health is necessary to the creation of gender sensitive and culturally appropriate interventions of public health surveillance that contribute to the elimination of ethnic inequalities in health.[14,17,21-23,29,42,43,47,51,55]

\section{Data Gaps and Recommendations}

- Current surveillance methods need to continue and include representative samples of subgroups in the Canadian population; the heterogeneity of women and men experiencing migration requires that large enough samples of women and men from different countries of birth as well as countries of origin are selected so that culturally sensitive conclusions can be drawn and allow for a proper analysis of the health determinants of women from diverse ethnic backgrounds and/or experiences of migration.

- Migration experience needs to be conceptualized according to the results of past studies and included as a social determinant of health above and beyond ethnicity and culture. It is expected that the upcoming longitudinal survey of immigrants will help enhance surveillance capacity in this area.

- In order to account for the cultural differences in the pathways of experiencing health and chronic conditions and because these experiences are relational and illustrate the underlying mechanisms for the differential distribution of health by socio-economic position, it is important to adopt not only a gender sensitive approach to the development of indicators but also a broader diversity interpretation of the health effects of potential advantageous and disadvantageous conditions - for example, to try and account for the social capital of women and men who undergo experiences of migration (network, resilience, ease of access, differential degree of control of resources by women, men and other members of the family).

- Issues such as accessibility (cultural, geographic, linguistic, financial), appropriateness and adequacy of health services are unlikely to be unique to women and men experiencing migration and need to be systematically accounted for.

- There should be consideration of the underlying socioeconomic and socio-political forces that shape the life conditions of women and men who are from a diverse background and/or undergo migration.

- Variables need to be constructed to allow women and men to best identify themselves appropriately according to ethnic identity and number of years in the host country; some of the proposed categories used as a cultural group may simply refer to skin colour without capturing associated elements of culture, ethnicity and life experiences.

- Variables need to be constructed to reflect the ability to cope with a physically or psychologically hazardous work environment, which has been shown to be associated with a better trajectory of healthy life in a new country and/or culture.

- Research designs need to account for the fact that reporting of perceived health and presence of chronic conditions is sensitive to gender, culture and ethnicity as well as migration experience.

- A variety of research strategies are needed that should include a diversity of women and men to collaborate in the development, design, and implementation of national monitoring.

\section{References}

I. Health Canada: Health Canada's gender-based analysis policy. Ottawa: Minister of Public Works and Government Services 2000.

2. Broom D: The genders of health. Paper presented at the conference "Gender, Health and Healing: Reflection on the Public-Private Divide', University of Warwick. National Centre for Epidemiology and Population Health, Australian National University 1999.

3. Condition féminine Canada: Analyse comparative entre les sexes: Guide d'élaboration des politiques. Ottawa: Condition féminine Canada 1996.

4. Conseil du statut de la femme du Québec. Document de réflexion sure l'intégration des femmes et des dossiers de condition féminine dans les structures décentralisées (recherche et rédaction; Mariangela DiDomenico). Québec: CSF 1995.

5. Santé Canada: Stratégie pour la santé des femmes. Ottawa: Minister of Public Works and Government Services 1999.

6. Standing H: Framework for understanding gender inequalities and health sector reform: an analysis and review of policy issues. Institute of Development Studies, University of Sussex. England 1999.

7. Zambrana R: A research agenda on issues affecting poor and minority: a model for understanding their needs. Women and Health 1988: 12.

8. Statistics Canada: 200 I Census: Analysis Series, Canada's ethnocultural portrait - the changing mosaic. Ottawa: Statistics Canada, Census Operations Division 2003. 
9. Citizenship and Immigration Canada: Facts and figures - immigration overview. Ottawa: Policy, Planning and Research, Citizenship and Immigration Canada 2002.

10. Davey-Smith G: Learning to live with complexity: Ethnicity, Socioeconomic position, and Health in Britain and the United States. Am J Public Health 2000, 90:1694-98.

II. Sheth T, Nargundkar M, Chagani K, Anand S, Nair C, Yusuf S: Classifying ethnicity utilizing the Canadian Mortality Data Base. Ethnicity \& Health 1997, 2:287-95.

12. Chen J, Wilkins R, Ng E: Health expectancy by immigrant status, I986 and I99I. Health Rep 1996, 8(3):29-38.

13. Dunn JR, Dyck I: Social determinants of health in Canada's immigrant population: results from the National Population Health Survey. Soc Sci Med 2000, 5 I:1573-93.

14. Hyman I: Immigration and health. Health Policy Working Paper Series. Ottawa ON: Health Canada 200I.

15. Kinnon D: Canadian research on immigration and health - an overview. Ottawa ON: Health Canada 1999.

16. Mulvihill MA, Mailloux L, Atkin W: Advancing policy and research responses to immigrant and refugee women's health in Canada. Program of the Centres of Excellence for Women's Health. Ottawa: Women's Health Bureau and the Research Management and Dissemination Division, Health Canada 2002.

17. Kinnon D: The Metropolis Project across Canada. Policy Research Initiatives 2001, 5(2 I5-17 [http://www.metropolis.net.].

18. Stover G: Colorful communities: toward a language of inclusion. Am J Public Health 2002, 92(4):512-14.

19. Chaturvedi N, McKeige PM: Methods for epidemiological surveys of ethnic minority groups. I Epidemiol Community Health |994, 48(2): |07-II.

20. Vissandjée B, Dupéré S: Culture, migration et enquête: défis incontournables. J Int Migration and Integration 2000, I (4):477-92.

21. Vissandjée B, Weinfeld M, Dupéré S, Abdool S: Sex, gender, ethnicity and access to health care services: research and policy challenges for immigrant women in Canada. J Int Migration and Integration 2000, 2(I):55-75.

22. Krieger $\mathrm{N}$, et al.: Racism, sexism and social class: implications for studies of health, disease and well-being? Am J Prev Med 1993, 9(S6):82-122

23. Krieger N: Discrimination and health. In In Social epidemiology Edited by: Berkman L, Kawachi I. Oxford: Oxford University Press; 2000:36-75.

24. Fassin D: La discrimination en pratiques; sources, processus et objets. In Un traitement inégal - Les discriminations dans l'accès aux soins. Les rapports d'étude du CRESP 2001:53-76.

25. Fall MN: Des citoyens qui ne chantent pas la marseillaise. In: Conditions et genres de vie; chroniques d'une autre France. Rapport du laboratoire d'analyse socio-anthropologique du risque 2000:406-4I5.

26. Fall K, Turgeon L: Champ mulitculturel, transactions interculturelles. Des théories, des pratiques et des analyses. Paris: L'Harmattan 1998.

27. Krieger N, Davey-Smith G: Re: Seeking causal explanations in social epidemiology. Am J Epidemiol 2000, I 5 I : I I3-I 20.

28. Cooper $\mathrm{H}$ : Investigating socio-economic explanations for gender and ethnic inequalities in health. Soc Sci Med 2002, 54:693-706.

29. Nazroo JY: Genetic, cultural or socio-economic vulnerability? Explaining ethnic inequalities in health. In In The sociology of health inequalities Edited by: Bartley M, Blane D, Davey Smith G. Oxford: Blackwell Publishers; 1998.

30. Policies legacies, new directions and future challenges [http://www.migra tioninformation.org/profiles/display.cfm.].

31. Citizenship and Immigration Canada: Immigration and Refugee Protec tion Act. Ottawa: Minister of Public Works and Government Services Canada 2002 [http://www.cic.gc.ca/english/irpa/.]

32. Citizenship and Immigration Canada: [http://geocities.yahoo.com]

33. Ng R: Gendering immigration/integration policy research. Toronto: Centre of Excellence in Immigration and Settlement (CERIS), National Conference on Immigration 1999.

34. Canadian Task Force on Mental Health Issues Affecting Immigrants and Refugees. After the door has been opened. Ottawa: Health and Welfare Canada, Multiculturalism and Citizenship Canada 1988.

35. Citizenship and Immigration Canada: Who can immigrate to Canada and the right to sponsor 2000 [http://cicnet.ci.gc.ca/english/pub/
[ immlaw.html.]
36. Anderson JM: Migration and health. Perspectives on immigrant women. Sociol Health Illness I999, 9(4):419-38.

37. Williams DR: Racial/ethnic variations in women's health: the social embeddedness of health. Am I Public Health 2002 92(4):588-97.

38. Molines C, et al.: Santé perçue et migration. Revue d'épidémiologie et de santé publique 2000, 48: |45-55.

39. Meleis Al: Immigrant transitions and health care: an action plan. Nurs Outlook 1997, 45(I):42.

40. Meadows LM, Thurston WE, Melton C: Immigrant women's health. Soc Sci Med 200I, 52:1451-58.

4I. Miediema J, Baukje Y, Tastsoglou E: But where are you from, originally? immigrant women and integration in the Maritimes. Edmonton: PCERII 2000:2.

42. Nazroo J: The structuring of ethnic inequalities in health: economic position, racial discrimination and racism. Am J Public Health 2003, 93(2):277-84.

43. Karlsen S, Nazroo J: Relation between racial discrimination, social class and health among ethnic minority groups. $\mathrm{Am} J$ Public Health 2002, 92(4):624-3I.

44. Karlsen S, Nazroo J: Women's experience of racism: how race and gender interact. Canadian Research Institute for Advancement of Women (CRIAW) 1999 [http://www.criaw-icref.ca/indexFrame e.htm]

45. Gee GC: A multilevel analysis of the relationship between institutional and individual racial discrimination and health status. Am J Public Health 2002, 92(4):6I5-23.

46. Lynch J, Kaplan G: Socioeconomic position. In: Social epidemiology Edited by: Berkman LF, Kawachi I. Oxford: Oxford University Press; 2000.

47. Im EO, Meleis Al, Lee KA: Symptom experience during menopausal transition: low income Korean immigrant women. Women \& Health 1999, 29(2):53-67.

48. Gravel S, Battaglini A: Culture, santé et ethnicité: vers une santé publique pluraliste. Montréal: Régie régionale de la santé et des services sociaux de Montréal-Centre 2000.

49. Oxman-Martinez J, Abdool S, Loiselle-Léonard M: Immigration, women and health in Canada. Can I Public Health 2000 , 91(5):394-95.

50. Vissandjée $B$, Carignan $P$, Bourdeau-Marchand $M$ : Les nouvelles immigrantes et la santé. L'infirmière canadienne 1999 , 95(4):35-4I.

51. Nazroo J: The structuring of ethnic inequalities in health: economic position, racial discrimination, and racism. Am J Public Health 2003, 93(2):277-83.

52. Vissandjée $B$, Dallaire $M$ : Expérience d'un partenariat de recherche avec des femmes immigrantes? Can J Public Health 2003, 4(3):55-75.

53. Schulz A, Israel B, Williams D, Parker E, Becker A, James S: Social inequalities, stressors and self-reported health status among African American and white women in the Detroit metropolitan area. Soc Sci Med 2000, 5 I: 1639-53.

54. Smaje C: Health, race and ethnicity: making sense of the evidence. London: Kings Fund Institute 1995.

55. Nazroo J: The health of Britain's ethnic minorities. London: Policy Studies Institute 1997.

56. Fenton S, Hughes AO, Hine CE: Self-assessed health, economic status and ethnic origin. New Community 1995, 2 I (I):55-69.

57. Bobak M, Pikhart H, Rose R, Hertzman C, Marmot M: Socioeconomic factors, material inequalities, and perceived control in self-rated health: cross-sectional data from seven post-communist countries. Soc Sci Med 2000, 5 I:1343-50.

58. Shadbolt B: Some correlates of self-rated health for Australian women. Am J Public Health 1997, 87(6):95I-56.

59. Beland Y: Canadian Community Health Survey - methodological overview. Health Rep 2002, 3(3):9-I4.

60. Gushulak BD, MacPherson D: Health issues associated with the smuggling and trafficking migrants. J Immigrant Health 2000 , 2(2):67-8.

61. Lindstrom M, Sundquist $P$, Ostergreen O: Ethnic differences in self-reported health in Malmö in southern Sweden. J Epidemiol Community Health 2000, 55:97-103.

62. McGuire S: Global migration and health: eco-feminist perspectives. Adv Nurs Sci 1998, 2 I (2): |-6.

63. Pan-American Health Organization (PAHO) Health situation analysis and trends summary: country chapter summary from health in the Americas 1998 [http://www.paho.org/english/sha/prflcan.htm]. 
64. Noh S, Beiser M, Kaspar V, Hou F, Rummens J: Perceived racial discrimination, depression and coping: a study of Southeast Asian refugees in Canada. J Health Soc Behav 1999, 40: 193-207.

65. Beiser M, Crombie D, Masi R, Ocampo M: Resettlement issues of immigrants and refugees. CrossCurrents, Centre for Addiction and Mental Health, The Journal of Additction and Mental Health 200I, 4(6): I3.

66. Kliewer E, Kazanjian A: The health status and medical services utilization of recent immigrants to Manitoba and British Columbia: a pilot study. Ottawa: Citizenship and Immigration Canada, BC Office of Health Technology Assessment 2000.

67. Berry JW, Kim J, Bosky P: Psychological acculturation of immigrants. In: Cross cultural adaptation. Current approaches. International and Intercultural Communication Annual 1987, I I:62-89.

68. Fullilove MT: Abandoning race as a variable in public health research - an idea whose time has come. Am J Public Health 1998, 88: 1297-98.

Publish with Biomed Central and every scientist can read your work free of charge

"BioMed Central will be the most significant development for disseminating the results of biomedical research in our lifetime. "

Sir Paul Nurse, Cancer Research UK

Your research papers will be:

- available free of charge to the entire biomedical community

- peer reviewed and published immediately upon acceptance

- cited in PubMed and archived on PubMed Central

- yours - you keep the copyright
BioMedcentral 